\title{
What's Sex Got to Do with It? The Role of Sexual Experience in the Sexual Attitudes, and Sexual Guilt and Anxiety of Young Muslim Adults in Canada and the United States
}

\author{
Sobia Ali-Faisal
}

University of Windsor

\section{Author Note}

Sobia F. Ali-Faisal, Department of Psychology, University of Windsor, Windsor, ON, Canada. The current research presents part of the results of the author's doctoral dissertation.

Sobia F. Ali-Faisal is now a postdoctoral fellow at Stony Brook University, Stony Brook, NY, US. I would like to acknowledge the Institute for Social Policy and Understanding for their financial support of this research. Additionally, much gratitude to my dissertation supervisor, Dr. Charlene Senn, for her guidance and help. Correspondence concerning this article should be addressed to Sobia F. Ali-Faisal atali1l@uwindsor.ca.

\section{Abstract}

The literature regarding sex and Muslims in North America is limited. The small body of research suggests that Muslims are relatively conservative regarding sex, though there is nuance in these findings. The current paper presents research on the association between sexual experience of young Canadian and American Muslims adults and their sexual attitudes, sexual guilt, and sexual anxiety. Participants were recruited online and a final sample of 403 young Muslims adults, mostly women, completed online surveys and a demographics questionnaire. 
Results revealed that more than half of participants had engaged in sexual intercourse, of which two-thirds had done so before marriage, while half of those who had not engaged in sex before marriage had thought about doing so. Analyses of variance were conducted to assess differences in sexual attitudes, sexual guilt, and sexual anxiety based on sexual experience. Young Muslim adults who had engaged in sexual intercourse held more liberal sexual attitudes, and reported less sexual guilt, and anxiety, than those who had not engaged in sexual intercourse. Similarly, those who had engaged in sex before marriage held more liberal sexual attitudes, and reported less sexual guilt and anxiety, than those who had waited until after marriage to have sex. Finally, those who had not had sex before marriage, but had thought about it, held more liberal sexual attitudes, and reported less sexual guilt and anxiety, than those who had not considered sex before marriage. These results indicate having sexual experience is associated with liberal sexual attitudes and relatively low levels of sexual guilt and anxiety. However, the directionality of this relationship is unclear, requiring further investigation. Despite the limitations of this study, the results have important implications for those working with young Muslim adults.

Keywords: Muslims, sexual guilt, sexual anxiety, sexual attitudes, sexual experience

Muslim youth growing up in a North American context negotiate a difficult sexual space which includes often conflicting messages regarding sexuality from Islam, from their cultures of origin, as well as the mainstream culture (Abu-Ali, 2003; Bekker et al., 1996; Ostberg, 2003; Sanjakdar, 2009a, 2009b); this situates Muslim youth in their own unique ethnocultural and religious identity groups. Yet, there is a dearth of empirical literature on the sexual experiences of Muslim youth living in North America, posing a problem for addressing Muslims' sexual health, especially psychological sexual health. The current paper presents research on the role sexual experiences may have in the sexual attitudes and sexual guilt and anxiety of young Muslim adults, in an effort to better understand and address psychological aspects of Muslims' sexual health.

\section{Sexual Attitudes of Muslims}

Research findings of the limited research on the sexual attitudes of Muslims living in the United States and Canada suggest that Muslims are a sexually conservative population. In a study of adolescent Muslim girls in the United States, Abu-Ali (2003) found that greater adherence to Islamic practices, rituals, and beliefs related to more conservative attitudes toward sexuality, and that religiosity was a significant predictor of these conservative attitudes. This comes 
as no surprise as the research finds that the more religious individuals report themselves to be, the more conservative their sexual attitudes (e.g., Hong, 1983; Lefkowitz, Gillen, Shearer, \& Boone, 2004; Maret \& Maret, 1982; Medora \& Burton, 1981; Miller \& Olson, 1988). Research also suggests that Muslims living in Western countries (i.e., Britain, Australia) are more sexually conservative when compared to those of other religions, finding Muslims report engaging in significantly less premarital sex, being less tolerant of premarital sex (de Visser, Smith, Richters, \& Rissel, 2007), and being more likely to believe premarital sex is wrong (Griffiths et al., 2011) than non-Muslim individuals.

\section{Sexual Guilt and Anxiety of Muslims}

Sexual guilt and anxiety are negative sexual affective-cognitive states, comprising a psychological aspect of sexual health. Sexual guilt is defined as a type of self-imposed punishment one assigns for either violating or anticipating the violation of one's standards of proper sexual conduct (Mosher \& Cross, 1971), while sexual anxiety is an expectancy for external punishment for violating, or anticipating violating, perceived societal normative standards of acceptable sexual behavior (Janda \& O'Grady, 1980). Both concepts have been linked to decreased sexual health. Sexual anxiety has long been thought to play an important role in the sexual dysfunction of both men and women (Aluja, 2004; Beggs, Calhoun, \& Wolchik, 1987; Hensel, Fortenberry, O'Sullivan, \& Orr, 2011), and at extreme levels can become a clinically disordered experience leading to sexual dysfunction and requiring therapeutic attention (e.g., Everaerd \& Dekker, 1982; Mccabe, 1992; Munjack, 1984; Nemetz, Craig, \& Reith, 1978; White, Fichtenbaum, \& Dollard, 1967). Sexual guilt has been implicated in decreased sexual drive and satisfaction and increased sexual dysfunction (Cado \& Leitenberg, 1990; Darling, Davidson, \& Passarello, 1992; Galbraith, 1969; Merrell, 2009; Morokoff, 1985; Nobre \& Pinto-Gouveia, 2006; Woo, Brotto, \& Gorzalka, 2011), and less sexual behavior including sexual intercourse (Love, Sloan, \& Schmidt, 1976). Considering lower sexual frequency has been found to be related to higher rates of divorce (Yabiku \& Gager, 2009) the presence of sexual guilt could create marriage instability. However, as the literature on the sexual guilt and anxiety of Muslims is nonexistent, the presence and level of sexual guilt and anxiety among Muslims is unknown.

\section{Sexual Experiences of Muslims}

The research on Muslims' sexual experiences is as limited as that on their sexual attitudes, though findings mirror Muslims' relative conservatism. Muslims 
are less likely to report having engaged in premarital sex than Jewish (Adamczyk \& Hayes, 2012) or Christian respondents (Adamczyk \& Hayes, 2012; Agha, 2009). As research has already established a relationship between conservative sexual attitudes and less sexual experience (Miller \& Olson, 1988; Oliver \& Hyde, 1993; Zuckerman, Tushup, \& Finner, 1976), it is not surprising that Muslims' sexual experiences parallel their sexual attitudes. However, the literature also suggests some nuance. Bangladeshi British young women and men interviewed in a qualitative study generally felt that engaging in premarital sex was un-Islamic, but not all chose to adhere to what they felt were Islamic teachings regarding premarital sex. Although some of the young men favored following religious recommendations, many participants, both men and women, felt that the choice to have premarital sex was personal and that doing so did not mean one lacked faith (Griffiths, French, Patel-Kanwal, \& Rait, 2008). Although many young Muslim adults may have conservative sexual attitudes and behaviors, it would be a mistake to conclude that sex is not a part of their lives. Indeed, in a recent study, Ahmed (2014) found 53.8\% of never-married Muslim college students in the United States reported engaging in sexual intercourse, with no significant difference between men and women. It is clear, therefore, that Muslims' psychological sexual health is in need of attention and investigation. Research on non-Muslim populations suggests increased sexual experience is related to decreased sexual anxiety (Hensel, Fortenberry, O'Sullivan, \& Orr, 2011; Morrison, Harriman, Morrison, Bearden \& Ellis, 2004), while sexual guilt is related to less sexual experience (D’Augelli \& Cross, 1975; Gerrard, 1987; Mosher, 1979a; Sack et al., 1984). It is unclear, however, whether this relationship will hold for Muslims. Therefore, this paper presents data on Muslims' sexual attitudes, sexual guilt, and sexual anxiety and the role sexual experience may play for Muslims. Specifically, this research seeks to examine how these factors relate to each other, and intends to provide insights into a specific aspect of the sexuality of young Muslim adults in the United States and Canada, enabling a better understanding of the sexual health of this population. Based on previous research conducted on non-Muslim populations, I hypothesized that young Muslim adults with sexual experience would hold more liberal sexual attitudes and would report less sexual guilt and anxiety than those with no sexual experience.

\section{Method}

\section{Participants}

The sample consisted of 403 heterosexual Canadian and American young adult Muslim women $(\mathrm{n}=320)$ and men $(\mathrm{n}=82)$ between the ages of 17 and $35(M=$ 
25.44; $S D=4.80$ ). One participant identified as transgender. Most participants lived in the United States or Canada and were a relatively educated population. Approximately one-third of the participants were born outside of Canada or the United States and indicated moving to Canada or the United States at a mean age of 10.11 years $(S D=7.23)$. The participants were an ethnically diverse population with most participants identifying as South Asian or Arab. For more details on participant demographics please see Table 1.

\section{Measures}

Demographics and Sexual Experience. The 25-item demographics questionnaire asked participants to report on various demographic variables including their sexual experience, gender, age, ethnocultural group, education level, country of residence, country of birth, sexual orientation, and relationship status.

Sexual Experience before Marriage. Two sets of questions with dichotomous response options of 'yes' or 'no' were also included to assess the presence of sexual experience before marriage. Respondents were asked "Have you had sex before marriage?" If they answered 'no' they were asked if they had considered premarital sex.

Brief Sexual Attitudes Scale (BSAS). The 23-item BSAS (Hendrick \& Hendrick, 2011; Hendrick, Hendrick, \& Reich, 2006) is a multidimensional scale to assess sexual attitudes and consists of four subscales. For the current study, the entire scale was administered but only the 10-item, 5-point Likert scale, Permissiveness subscale, assessing an open and casual attitude toward sex, was relevant and included in the analysis. This subscale has been used independently in other research (e.g., Brelsford, Luquis, \& Murray-Swank, 2011; Tobin, 2011) and had high validity for the current study (Cronbach's alpha was $.90)$.

\section{Revised Mosher Guilt Inventory (RMGI) - Sex-Guilt Subscale} (Revised). ${ }^{1}$ The 50 -item sexual guilt measure is a subscale of the 114 item RMGI (Mosher, 2011) with each item using a 7-point Likert scale and consisting of a sentence completion stem with a pair of responses, in which one response represents presence of guilt while the other represents non-guilt. The use of the subscale separately has been approved (Mosher, 1979b, as cited in Mosher, 2011). Using feedback obtained from all-Muslim focus groups in a pilot study (not described here), 16 more items were added to this measure to make it a 66-item measure. The Cronbach's alpha for this study was .97.

1. As questions were added to both the Sexual Guilt Subscale and the Sex Anxiety Inventory, both measures were assessed using a principle component analysis (not described here). As a result, four items were removed from the Sex Guilt Subscale, for a total of 62 items, and two items were removed from the Sex Anxiety Inventory, for a total of 25 items. All other measures remained the same. 
Sex Anxiety Inventory (SAI). This 25 -item, forced choice measure presents sentence completion stems with two possible response options (Janda \& O'Grady, 1980). Respondents choose one of the two options which is closest to describing their feelings regarding sex; one response option reflected sexual anxiety (score of one) and the other reflected no sexual anxiety (score of zero). Based on the feedback of the focus groups in the pilot study, two more questions were added to this measure for the purpose of the current study, resulting in a 27-item measure. The Cronbach's alpha for this study was .86.

\section{Procedure}

Data was collected using online surveys, using best practices in online data collection (Granello \& Wheaton, 2004). Participants were recruited online, across Canada and the United States. Respondents were provided with a link to the study website where they were first presented with a brief electronic letter of information which included the option to accept the terms of the study and continue, or to not accept and exit the study. Acceptance served as informed consent. Those who continued were asked to complete a demographics questionnaire followed by the surveys.

\section{Results}

Sexual experience

More than half of the participants reported having engaged in sexual intercourse (54.8\%). Of those who had engaged in sex, two-thirds had done so before marriage (67\%). Among those who had not engaged in sex before marriage, half had thought about doing so $(50.2 \%)$. When examined by gender it was found that around two-thirds of the women and men who had had sex had done so before marriage (68.4\% and $60.5 \%$, respectively). However, among those who had not had sex before marriage, almost two-thirds of men had thought about doing so (64.3\%) compared to fewer than half the women (46.2\%). Please see Table 1 for details.

\section{Sexual Experience and Sexual Attitudes, Guilt, and Anxiety}

Correlational analysis revealed positive correlations of sexual attitudes with sexual guilt $(r=.635, \mathrm{p}<.01)$ and sexual anxiety $(r=.591, \mathrm{p}<.01)$, such that more conservative sexual attitudes related to higher levels of sexual guilt and anxiety. Sexual guilt and sexual anxiety were also strongly correlated with each other $(r=.80, \mathrm{p}<.01)$. Analysis of variance tests were conducted to assess any differences in attitudes and sexual guilt and anxiety based on sexual experi- 
Table 1. Demographics of Study Participants

\begin{tabular}{|c|c|c|}
\hline Demographics & $\begin{array}{c}\text { Total } \\
N=403\end{array}$ & $\%$ \\
\hline \multicolumn{3}{|l|}{ Country of residence } \\
\hline Canada & 135 & 33.5 \\
\hline United States & 260 & 64.5 \\
\hline Other & 7 & 1.7 \\
\hline \multicolumn{3}{|l|}{ Ethnic group identification } \\
\hline South Asian & 175 & 43.4 \\
\hline Arab & 101 & 25.1 \\
\hline European & 30 & 7.4 \\
\hline African American/Canadian & 24 & 6.0 \\
\hline Multiple ethnicities & 22 & 5.6 \\
\hline Other & 51 & 12.7 \\
\hline \multicolumn{3}{|l|}{ Birthplace } \\
\hline Canada & 82 & 20.3 \\
\hline United States & 180 & 44.7 \\
\hline Other & 139 & 34.5 \\
\hline \multicolumn{3}{|l|}{ Level of Education } \\
\hline$\leq$ High school & 4 & 1.0 \\
\hline High school diploma & 20 & 4.9 \\
\hline Some university or college & 76 & 18.9 \\
\hline College diploma/Associate's degree (U.S. only) & 21 & 5.2 \\
\hline Undergraduate degree & 130 & 32.3 \\
\hline Graduate degree & 150 & 37.2 \\
\hline \multicolumn{3}{|l|}{ Relationship Status } \\
\hline Single/no previous relationship & 98 & 24.3 \\
\hline Single/relationship in the past & 87 & 21.6 \\
\hline Married & 114 & 28.3 \\
\hline Dating & 64 & 15.9 \\
\hline Engaged & 20 & 4.9 \\
\hline Divorced & 11 & 2.7 \\
\hline Common-law & 2 & 0.5 \\
\hline Other (e.g., separated, widowed and divorced) & 4 & 1.0 \\
\hline \multicolumn{3}{|l|}{ Sexual Experience } \\
\hline Sexually experienced/Had sexual intercourse & 221 & 54.8 \\
\hline Women & 177 & 55.3 \\
\hline Men & 41 & 50.0 \\
\hline Had sex before marriage & 148 & 36.7 \\
\hline Women & 121 & 37.8 \\
\hline Men & 26 & 31.7 \\
\hline Did not have sex before marriage & 253 & 62.8 \\
\hline Women & 197 & 61.5 \\
\hline Men & 56 & 68.3 \\
\hline Thought about having sex before marriage & 127 & 31.5 \\
\hline Women & 91 & 28.4 \\
\hline Men & 36 & 43.9 \\
\hline Did not think about sex before marriage & 126 & 31.3 \\
\hline Women & 105 & 32.8 \\
\hline Men & 21 & 25.6 \\
\hline \multicolumn{3}{|l|}{ Source of Sexual Education } \\
\hline Received sex education at the mosque & 17 & 4.2 \\
\hline Women & 14 & 4.4 \\
\hline Men & 3 & 3.7 \\
\hline Received sex education at school & 307 & 76.2 \\
\hline Women & 239 & 74.7 \\
\hline Men & 67 & 81.7 \\
\hline
\end{tabular}

Note. Women $n=320$, Men $n=82$. Participants included in the category "Thought about having sex before marriage" were those who reported not having had sex before marriage. 
ence. The Games-Howell post-hoc procedure was used with a significance value of .05. Please see Table 2 for all means and standard deviations. Those who reported having had sexual intercourse held significantly more liberal personal sexual attitudes, $F(1,398)=11.81, p<.01$, and reported less sexual guilt, $F(1$, $398)=32.34, p<.001$, and sexual anxiety, $F(1,398)=83.47, p<.001$, than those who had not had sexual intercourse.

Participants who had had sex before marriage held more liberal sexual attitudes, $F(1,399)=42.760, p<.001$, and reported less sexual guilt, $F(1,399)=$ $78.76, p<.001$, and sexual anxiety, $F(1,399)=82.22, p<.001$ than those who had not had sex before marriage. Similarly, those who had sex before marriage held more liberal sexual attitudes, $F(1,218)=24.46, p<.001$, and experienced less sexual guilt, $F(1,218)=41.03, p<.001$, and sexual anxiety, $F(1,218)=$ $15.28, p<.001$, than those who had waited until marriage to have sex. Finally, those who reported they had not had sex before marriage, but had considered it held more liberal sexual attitudes, $F(1,251)=37.34, p<.001$, and reported less sexual guilt, $F(1,251)=57.60, p<.001$ and sexual anxiety, $F(1,251)=$ $39.49, p<.001$ than those who had not had sex before marriage and had not considered sex before marriage.

\section{Discussion}

Research on the sexual experiences, attitudes, guilt and anxiety of Muslims in Canada and the United States is virtually nonexistent. The results of this study provided some intriguing potential insights on young Muslim adults. Most young Muslim adults who reported being sexually experienced had engaged in sexual intercourse before marriage. Other recent research has found that, when asked, more than half of never-married Muslim college students in the United States reported engaging in sexual intercourse (Ahmed, 2009). The results of the current study paint an informative and illuminating picture of the sexual experience of these young Muslim women and men and its relationship to their sexual attitude and their levels of sexual guilt and sexual anxiety.

It was clear that having sexual experience was related to more liberal sexual attitudes and less worry about harsh judgement from oneself (sexual guilt) and from others (sexual anxiety). These results mirror research conducted with non Muslim groups, which has found greater sexual experience to be related to lower levels of both sexual guilt (D’Augelli \& Cross, 1975; Gerrard, 1987; Mosher, 1979a; Sack et al., 1984) and sexual anxiety (Hensel et al., 2011), as well as liberal sexual attitudes (Miller \& Olson, 1988; Oliver \& Hyde, 1993; Zuckerman et al., 1976). However, the differences found on sexual attitudes, guilt, and anxiety based on when sexual intercourse occurred, as well as differences based on the consideration of engaging in sex before marriage, were quite noteworthy. Those who had 


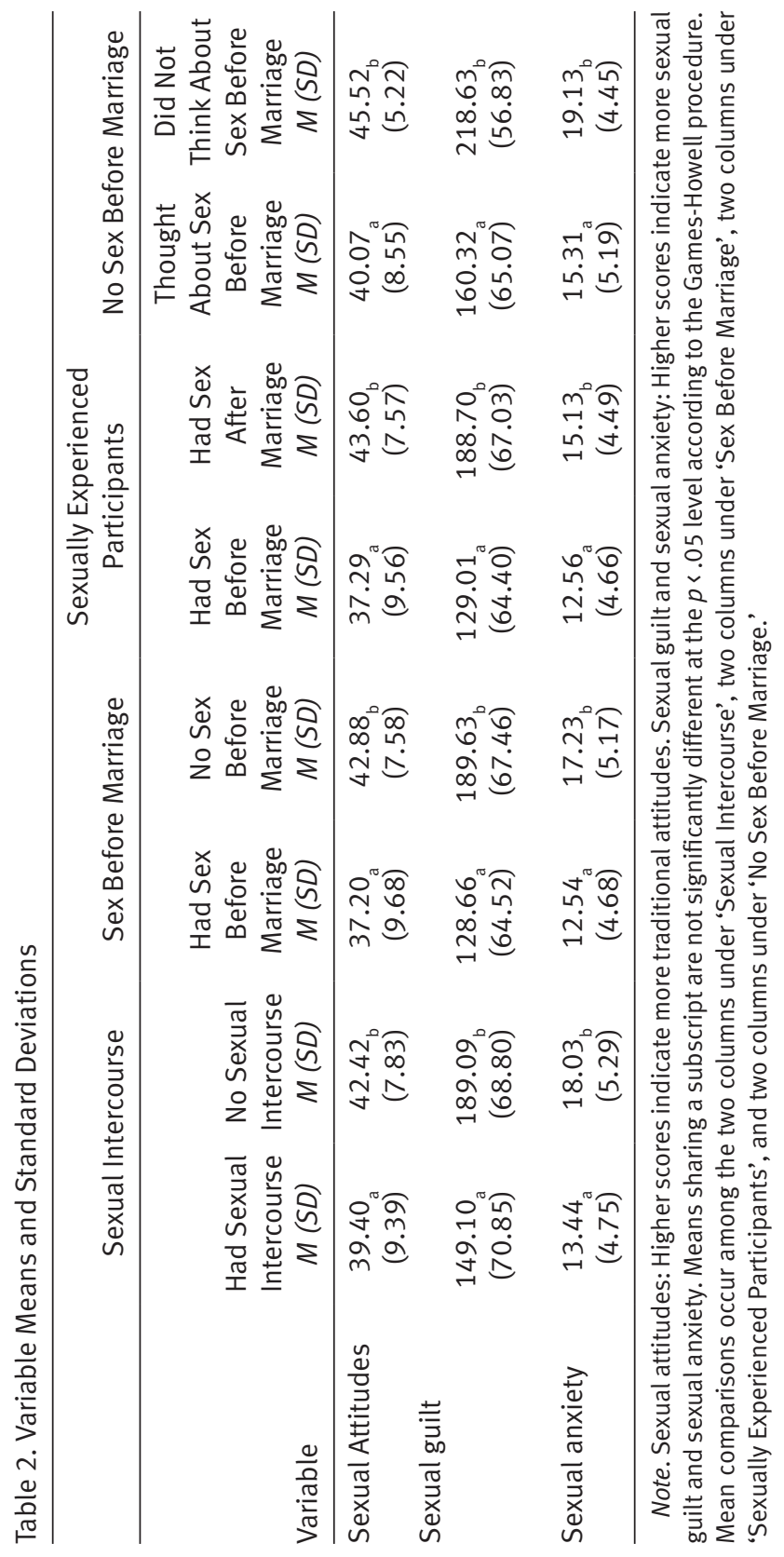


sexual experience before marriage held more liberal sexual attitudes and reported less sexual guilt and anxiety than those who had waited until after marriage to engage in sex. Those who had thought about having sex before marriage held more liberal sexual attitudes and less sexual guilt and anxiety than those who had not thought about doing so. Similarly, permissive sexual attitudes have been found to predict intention to engage in premarital sex among non-Muslims as well (Cha, Doswell, Kim, Charron-Prochownik, \& Patrick, 2007). Although it is clear that an association occurs between sexual experience and sexual attitudes, guilt, and anxiety, the directionality of such an association is unclear. However, the literature appears to suggest a bidirectional relationship. In a longitudinal study Hensel and colleagues (2011) followed African-American adolescent women over four years and found that as these young women gained sexual experience, their levels of sexual anxiety decreased. The researchers speculated that as these young women gained sexual experience they also gained sexual confidence (i.e., having a positive evaluation of one's sexuality, sexual thoughts, feelings, and behaviors, and one's body in a sexual context), which may have resulted in decreased levels of sexual anxiety. These decreased levels of sexual anxiety may then have created a positive environment in which the women felt comfortable engaging in more sexual behaviors. Nonetheless, further research is required to explore this association among Muslims.

\section{Limitations}

The first limitation of this study was that the sample was highly educated and therefore relatively privileged. The second limitation was the lack of gender diversity as the sample consisted mainly of Muslim women, despite efforts made to recruit more Muslim men. As the focus was on the relationship of sexuality related constructs with sexual experience, religiosity was not included in this analysis, which was the third limitation. The final limitation was the use of a convenience sample, which reduces generalizability. As participants self-selected into the study, this sample may have had more concern with issues of sex and sexuality than those who chose not to participate (Wolchik, Braver, \& Jensen, 1985), thus potentially making this sample unrepresentative. In addition, as data collection was conducted online, the sample may have excluded those who were uncomfortable with this format or did not have access to the internet.

\section{Practice Implications}

The results of this study have many practical implications for Muslims in North America as well as those who work with Muslim populations, both from with- 
in and outside the Canadian and American Muslim communities, including practitioners, religious clergy, leaders, educators, and community workers. As mentioned previously, sexual dysfunction is often associated with sexual guilt and sexual anxiety. This relationship becomes all the more concerning given that, in women especially, decreased sexual functioning and dissatisfaction have been associated with decreased relationship (Witting et al., 2008) and marital satisfaction (Brezsnyak \& Whisman, 2004; Trudel \& Goldfarb, 2010). As rates of divorce among Muslims in North America rise (Macfarlane, 2012), understanding a possible role of sexual guilt and anxiety in marital discord could help counter this trend.

These findings suggest that sexual experience, including sex before marriage, are related to less fear of harsh self-judgement and judgement from others. However, advocating for young Muslim adults to engage in more sexual activities or sex before marriage as a means of reducing sexual guilt and anxiety levels would not only be unreasonable and unrealistic, it may also be offensive to many and premature as the direction of this relationship has not been established. As mentioned previously, Hensel and colleagues (2011) found increased sexual experience to result in decreased levels of sexual anxiety, speculating the decrease in sexual anxiety may have been related to an increase in sexual confidence. Therefore, attempts at decreasing the sexual anxiety, as well as sexual guilt, of young Muslim adults may be accomplished by creating methods of increasing their sexual confidence while remaining religiously and culturally sensitive, through educational programs and workshops, supportive groups and networks of peers and experts, and online and social media resources created by Muslim community workers. As abstinence-only educational programs have been found to be relatively ineffective at influencing sexual behaviors of adolescents (Kohler, Manhart, \& Lafferty, 2008), educational programs from the community should be comprehensive and include factual information.

\section{Future Directions in Research}

Future research should examine the role of sexual experiences with more depth. Details about the meaning of sexual experience for Muslims could be gathered, providing a more complex understanding of the construct. As research suggests that contextual factors surrounding first intercourse may impact sexual guilt (Else-Quest, Shibley Hyde, \& DeLamater, 2005), examining the context of sexual experience would provide greater insight into the issue. In addition, further exploration of the direction of the relationship between sexual experience and sexual guilt and anxiety should be undertaken, using longitudinal research methods to uncover the order in which events may occur. 


\section{Conclusion}

The sexual attitudes, sexual guilt, and sexual anxiety of young Muslims adults are associated with their sexual experience such that those reporting experience are more liberal in their attitudes, with less self-reported degrees of guilt and anxiety than those without experience. As presence of sexual guilt and anxiety can be detrimental to the sexual health of individuals, understanding this association may be helpful in addressing the sexual health of young Muslim adults.

\section{References}

Abu-Ali, A. (2003). Ethnic identity and religiosity as predictors of sexual attitudes among Muslim adolescent girls. Alliant International University.

Adamczyk, A., \& Hayes, B. E. (2012). Religion and Sexual Behaviors: Understanding the Influence of Islamic Cultures and Religious Affiliation for Explaining Sex Outside of Marriage. American Sociological Review, 77(5), 723-746. http://doi. org/10.1177/0003122412458672

Agha, S. (2009). Changes in the timing of sexual initiation among young muslim and christian women in Nigeria. Archives of Sexual Behavior, 38(6), 899-908. http:// doi.org/10.1007/s10508-008-9395-0

Ahmed, S. (2009). Religiosity and Presence of Character Strengths in American Muslim Youth. Journal of Muslim Mental Health, 4(2), 104-123. http://doi. org/10.1080/15564900903245642

Aluja, A. (2004). Sensitivity to punishment, sensitivity to reward and sexuality in females. Personality and Individual Differences, 36(1), 5-10. http://doi.org/10.1016/ S0191-8869(02)00219-2

Beggs, V. E., Calhoun, K. S., \& Wolchik, S. a. (1987). Sexual anxiety and female sexual arousal: A comparison of arousal during sexual anxiety stimuli and sexual pleasure stimuli. Archives of Sexual Behavior, 16(4), 311-319. http://doi.org/10.1007/ BF01542140

Bekker, M. H. J., Rademakers, J., Mouthaan, I., De Neef, M., Huisman, W. M., Van Zandvoort, H., \& Emans, A. (1996). Reconstructing hymens or constructing sexual inequality? Service provision to Islamic young women coping with the demand to be a virgin. Journal of Community and Applied Social Psychology, 6(5), 329-334. http://doi.org/10.1002/(SICI)1099-1298(199612)6:5<329::AIDCASP383>3.0.CO;2-B

Brelsford, G. M., Luquis, R., \& Murray-Swank, N. a. (2011). College Students' Permissive Sexual Attitudes: Links to Religiousness and Spirituality. International Journal for the Psychology of Religion, 21(2), 127-136. http://doi.org/10.1080/10508619. 2011.557005

Brezsnyak, M., \& Whisman, M. A. (2004). Sexual desire and relationship functioning: The effects of marital satisfaction and power. Journal of Sex \& Marital Therapy, 30, 199-217. https://doi.org/10.1080/00926230490262393

Cado, S., \& Leitenberg, H. (1990). Guilt reactions to sexual fantasies during intercourse. Archives of Sexual Behavior, 19(1), 49-63. http://doi.org/10.1007/BF01541825 
Cha, E. S., Doswell, W. M., Kim, K. H., Charron-Prochownik, D., \& Patrick, T. E. (2007). Evaluating the Theory of Planned Behavior to explain intention to engage in premarital sex amongst Korean college students: A questionnaire survey. International Journal of Nursing Studies, 44(7), 1147-1157. http://doi.org/10.1016/j. ijnurstu.2006.04.015

Darling, C. A., Davidson, J. K., \& Passarello, L. C. (1992). The mystique of first intercourse among college youth: The role of partners, contraceptive practices, and psychological reactions. Journal of Youth and Adolescence, 21(1), 97-117. http:// doi.org/10.1007/BF01536984

de Visser, R. O., Smith, A. M. A., Richters, J., \& Rissel, C. E. (2007). Associations between religiosity and sexuality in a representative sample of Australian adults. Archives of Sexual Behavior, 36(1), 33-46. http://doi.org/10.1007/s10508-0069056-0

Else-Quest, N. M., Shibley Hyde, J., \& DeLamater, J. D. (2005). Context counts: Longterm sequelae of premarital intercourse or abstinence. Journal of Sex Research, 42, 102-112. http://doi.org/10.1080/00224490509552263

Everaerd, W., \& Dekker, J. (1982). Treatment of secondary orgasmic dysfunction: A comparison of systematic desensitization and sex therapy. Behaviour Research and Therapy, 20(3), 269-274. http://doi.org/10.1016/0005-7967(82)90145-0

Galbraith, G. G. (1969). The Mosher sex-guilt scale and the Thorne sex inventory: intercorrelations. Journal of Clinical Psychology, 25(3), 292-294. https://doi. org/10.1002/1097-4679(196907)25:3<292::AID-JCLP2270250321>3.0.CO;2-C

Granello, D. H., \& Wheaton, J.E. (2004). Online Data Collection :Strategies for Research. Practice and Theory, 82, 387-393. https://doi.org/10.1002/j.1556-6678.2004. tb00325.x

Griffiths, C., French, R. S., Patel-Kanwal, H., \& Rait, G. (2008). "Always between two cultures": young British Bangladeshis and their mothers' views on sex and relationships. Culture, Health \& Sexuality, 10(7), 709-723. http://doi. org/10.1080/13691050802213571

Griffiths, C., Johnson, A. M., Fenton, K. A., Erens, B., Hart, G. J., Wellings, K., \& Mercer, C. H. (2011). Attitudes and first heterosexual experiences among Indians and Pakistanis in Britain: evidence from a national probability survey. International Journal of STD \& AIDS, 22(3), 131-139. http://doi.org/10.1258/ijsa.2009.009496

Hendrick, C., Hendrick, S. S., \& Reich, D. a. (2006). The brief sexual attitudes scale. Journal of Sex Research, 43(1), 76-86. http://doi.org/10.1080/00224490609552301

Hendrick, S. S., \& Hendrick, C. (2011). Sexual Attitudes Scale and Brief Sexual Attitudes Scale. In T. D. Fisher, C. M. Davis, W. L. Yarber, \& S. L. Davis (Eds.), Handbook of sexuality-related measures (3rd ed., pp. 71-74). New York: Routledge.

Hensel, D. J., Fortenberry, J. D., O’Sullivan, L. F., \& Orr, D. P. (2011). The developmental association of sexual self-concept with sexual behavior among adolescent women. Journal of Adolescence, 34(4), 675-684. http://doi.org/10.1016/j.adolescence.2010.09.005

Hong, S.-M. (1983). Gender, religion, and sexual permissiveness: Some recent Australian data. Journal of Psychology, 115(1), 17-22. https://doi.org/10.1080/00223980 .1983 .9923593

Janda, L. H., \& O'Grady, K. E. (1980). Development of a sex anxiety inventory. Journal of Consulting and Clinical Psychology, 48(2), 169-175. http://doi.org/10.1037//0022006X.48.2.169

Kohler, P. K., Manhart, L. E., \& Lafferty, W. E. (2008). Abstinence-Only and Com- 
prehensive Sex Education and the Initiation of Sexual Activity and Teen Pregnancy. Journal of Adolescent Health, 42(4), 344-351. http://doi.org/10.1016/j. jadohealth.2007.08.026

Lefkowitz, E. S., Gillen, M. M., Shearer, C. L., \& Boone, T. L. (2004). Religiosity, sexual behaviours, and sexual attitudes during emerging adulthood. Journal of Sex Research, 41(2), 150-159.

Love, R. E., Sloan, L. R., \& Schmidt, M. J. (1976). Viewing pornography and sex guilt: the priggish, the prudent, and the profligate. Journal of Consulting and Clinical Psychology, 44(4), 624-629. http://doi.org/10.1037/0022-006X.44.4.624

Macfarlane, J. (2012). Understanding trends in American Muslim divorce and marriage: A discussion guide for families and communities.

Maret, S. M., \& Maret, L. D. (1982). Attitudes of fundamentalists toward nonmarital sex. Psychological Reports, 51, 921-922. https://doi.org/10.2466/pr0.1982.51.3.921

Mccabe, M. P. (1992). A program for the treatment of inhibited sexual desire in males. Psychotherapy, 29(2), 288-296. https://doi.org/10.1037/0033-3204.29.2.288

Medora, N. P., \& Burton, M. M. (1981). Extramarital Sexual Attitudes and Norms of an Undergraduate Student Population. Adolescence, 16(62), 251-262.

Merrell, J. M. (2009). Study of the four factor theory of women's sexual function.

Miller, B., \& Olson, T. (1988). Sexual attitudes and behavior of high school students in relation to background and contextual factors. Journal of Sex Research, 24, 194-200. Retrieved from http://www.tandfonline.com/doi/ abs/10.1080/00224498809551411

Morokoff, P. J. (1985). Effects of sex guilt, repression, sexual "arousability," and sexual experience on female sexual arousal during erotica and fantasy. Journal of Personality and Social Psychology, 49(1), 177-187. http://doi.org/10.1037/00223514.49.1.177

Mosher, D. L. (1979). The meaning and measurement of guilt. In C. E. Izard (Ed.), Emotions in personality and psychopathology. New York: Plenum. https://doi. org/10.1007/978-1-4613-2892-6_5

Mosher, D. L. (2011). Revised Mosher Guilt Inventory. In T. D. Fisher, C. M. Davis, W. L. Yarber, \& S. L. Davis (Eds.), Handbook of sexuality-related measures (3rd ed., pp. 321-324). New York: Routledge.

Mosher, D. L., \& Cross, H. J. (1971). Sex guilt and premarital sexual experiences of college students. Journal of Consulting and Clinical Psychology, 36(1), 27-32. http:// doi.org/10.1037/h0030454

Munjack, D. J. (1984). Rational-emotive therapy in the treatment of erectile failure: An initial study. Journal of Sex \& Marital Therapy, 10, 170-175. https://doi. org/10.1080/00926238408405942

Nemetz, G. H., Craig, K. D., \& Reith, G. (1978). Treatment of female sexual dysfunction through symbolic modeling. Journal of Consulting and Clinical Psychology, 46(1), 62-73. http://doi.org/10.1037/0022-006X.46.1.62

Nobre, P. J., \& Pinto-Gouveia, J. (2006). Emotions during sexual activity: Differences between sexually functional and dysfunctional men and women. Archives of Sexual Behavior, 35(4), 491-499. http://doi.org/10.1007/s10508-006-9047-1

Oliver, M. B., \& Hyde, J. S. (1993). Gender differences in sexuality: a meta-analysis. Psychological Bulletin, 114(1), 29-51. http://doi.org/10.1037/0033-2909.114.1.29

Ostberg, S. (2003). Norwegian-Pakistani adolescents: Negotiating religion, gender, ethnicity and social boundaries. Young: Nordic Journal of Youth Research, 11(2), 161-181. https://doi.org/10.1177/1103308803011002004 
Sanjakdar, F. (2009a). Participatory action research: creating spaces for beginning conversations in sexual health education for young Australian Muslims. Educational Action Research, 17(2), 259-275. http://doi.org/10.1080/09650790902914233

Sanjakdar, F. (2009b). "Teacher talk": the problems, perspectives and possibilities of developing a comprehensive sexual health education curriculum for Australian Muslim students. Sex Education, 9(3), 261-275. http://doi. org/10.1080/14681810903059086

Tobin, C. T. (2011). Development of the Sexual Attitudes and Experiences Scale (SAES). College Student Journal, 45(2), 352-368.

Trudel, G., \& Goldfarb, M. R. (2010). Marital and sexual functioning and dysfunctioning, depression and anxiety. Sexologies, 19, 137-142. https://doi.org/10.1016/j. sexol.2009.12.009

White, A. M., Fichtenbaum, L., \& Dollard, J. (1967). Measured Relationships Between Sexual Motivation and Anxiety. Journal of Counseling Psychology, 14(6), 544549. http://doi.org/10.1037/h0025237

Witting, K., Santtila, P., Alanko, K., Harlaar, N., Jern, P., Johansson, A., . . Sandnabba, N. K. (2008). Female sexual function and its associations with number of children, pregnancy, and relationship satisfaction. Journal of Sex \& Marital Therapy, 34(2), 89-106. http://doi.org/10.1080/00926230701636163

Wolchik, S. a., Braver, S. L., \& Jensen, K. (1985). Volunteer bias in erotica research: Effects of intrusiveness of measure and sexual background. Archives of Sexual Behavior, 14(2), 93-107. http://doi.org/10.1007/BF01541656

Woo, J. S. T., Brotto, L. a., \& Gorzalka, B. B. (2011). The role of sex guilt in the relationship between culture and women's sexual desire. Archives of Sexual Behavior, 40(2), 385-394. http://doi.org/10.1007/s10508-010-9609-0

Yabiku, S. T., \& Gager, C. T. (2009). Sexual Frequency and the Stability of Marital and Cohabiting Unions. Journal of Marriage and Family, 71(4), 983-1000. http://doi. org/10.1111/j.1741-3737.2009.00648.x

Zuckerman, M., Tushup, R., \& Finner, S. (1976). Sexual attitudes and experience: attitude and personality correlates and changes produced by a course in sexuality. Journal of Consulting and Clinical Psychology, 44(1), 7-19. http://doi. org/10.1037/0022-006X.44.1.7 
